Clinica Chimica Acta, 65 (1975) 197-204

(C) Elsevier Scientific Publishing Company, Amsterdam - Printed in The Netherlands

CCA 7364

\title{
PERMANENT CHEMICAL PHENYLKETONURIA AND A NORMAL PHENYLALANINE TOLERANCE IN TWO SISTERS WITH A NORMAL MENTAL DEVELOPMENT
}

S.K. WADMAN ${ }^{a}$, D. KETTING ${ }^{a}$, P.K. DE BREE ${ }^{a}$, C. VAN DER HEIDEN ${ }^{a}$, M.TH. GRIMBERG ${ }^{\mathbf{b}}$ and H. KRUIJSWIJK ${ }^{\mathbf{b}}$

aUniversity Children's Hospital, Het Wilhelmina Kinderziekenhuis, Nieuwe Gracht 137, Utrecht and bonze Lieve Vrouwe Gasthuis, Amsterdam (The Netherlands)

(Received June 11, 1975)

\section{Summary}

A positive 'ferric chloride reaction was found at routine examination of the urine of a 14 year old mentally normal girl, admitted for complaints of headache and other meningitis-like symptoms.

It turned out that she excreted permanently increased amounts of phenylpyruvic, phenyllactic and o-hydroxyphenylacetic acids, but phenylacetic acid (free plus conjugated) was normal. Fasting serum phenylalanine was not increased nor was urinary phenylalanine. On loading with L-phenylalanine $(100 \mathrm{mg} / \mathrm{kg})$ a normal serum phenylalanine response followed, but urinary phenylpyruvic, phenyllactic and $o$-hydroxyphenylacetic acids increased further. Phenylacetic acid responded too, but remained in the normal range. In addition to the above-mentioned abnormalities the urine contained a still unidentified abnormal acid, which also increased after loading with phenylalanine.

Her 12 year old healthy sister showed the same chemical abnormality. Two older brothers and the parents had normal excretions. The enzyme defect has not been identified. As a possibility the defective decarboxylation of phenylpyruvic acid is proposed.

\section{Introduction}

In untreated classical phenylketonuria, patients have greatly increased plasma phenylalanine concentrations (up to $3 \mathrm{mM}$ and even higher) and excrete large amounts of phenylalanine (Phe), phenylpyruvic acid (PPyA), phenyllactic acid (PLA), o-hydroxyphenylacetic acid (o-OHPAA) and phenylacetic acid 
(PAA), completely or mainly as a glutamine conjugate. Also mandelic acid (MA) is increased. Milder variants of this disorder are known, showing the same chemical picture but at a lower level. The mildest form is hyperphenylalaninemia, without phenylketonuria, an asymptomatic trait. The chemical features are: increased plasma and urinary Phe only; the first less than $1 \mathrm{mM}$. In the urine the excretions of PPyA, PLA, O-OHPAA, PAA and MA are normal. For a survey of the hyperphenylalaninemic traits in man see ref. 1.

In the present paper we describe a new, probably inherited variant of phenylalanine metabolism, characterized by a permanently increased excretion of PPy A, PI.A, o-OHPAA and MA, but normal hlood and urinary phenylalanine and urinary PAA concentrations. This abnormality was discovered in a nearly 14 year old, mentally normal girl with transient and probably aspecific neurological complaints. Her 12 year old healthy sister showed the same chemical abnormality.

\section{Case report}

The patient W.Z. was a girl, who was admitted at the age of 13 years and 10 months for mainly meningitis-like symptoms, namely headache (which had already lasted 2 months), fever, drowsiness, apathy, neck-stiffness, pains in neck and limbs. The signs of Kernig and Brudzinski were positive. She recovered after having been treated with antibiotics.

According to the electroencephalographist the E.E.G. showed diffuse posttraumatic alterations, without definite focal abnormalities. At the age of 7 she twice had a commotio cerebri and, posttraumatically, a damaged cervical vertebra.

Psychomotor development was without problems. Intelligence was average. Physical development somewhat below normal: she belonged to the 30 th percentile of her age group.

Routine laboratory investigations were normal, except for urinary phenylpyruvic acid. The urine appeared to have a somewhat peculiar smell, therefore the ferric chloride reactions were carried out and were repeatedly positive. Plasma phenylalanine was normal, however, which excluded classical phenylketonuria (PKU) or a milder variant. At this stage detailed gas chromatographic and comparable quantitative methods were applied, which yielded the results given below.

Her 12 year old sister, who showed the same excretory abnormalities, was completely healthy.

In the patient's parents and in two older brothers of 17 and 18 no abnormal excretory pattern was present.

\section{Methods}

\section{Amino acids}

Amino acids were analyzed by automated quantitative column chromatography, using the Technicon TSM1 standard procedure. Also a rapid TSM1 procedure (54 minutes) for scrum phenylalanine and tyrosine was used.

Resin bed: $26 \mathrm{~cm}$; column diameter: $0.4 \mathrm{~cm}$; resin type: C3; column tem- 
perature: $63^{\circ} \mathrm{C}$; flow rate: $0.45 \mathrm{ml} / \mathrm{min}$; buffer: lithium $0.50 \mathrm{M}$; citrate: $0.05 \mathrm{M}$; $\mathrm{pH}: 3.45(\mathrm{HCl}) ; R_{\mathrm{t}}$ phenylalanine: $44 \mathrm{~min} ; R_{\mathrm{t}}$ tyrosine: $37 \mathrm{~min}$.

\section{Phenolic acids}

Phenolic acids were analyzed by 2-dimensional chromatography according to Armstrong et al. [2], but instead of filter paper $10 \mathrm{~cm} \times 10 \mathrm{~cm}$ thin-layer plates (D.C. Alufolien cellulose $0.1 \mathrm{~mm}$, E. Merck A.G. Darmstadt No. 5552) were used.

First solvent: isopropanol/ammonia $5 \%(8: 2)$. Second solvent: benzene/ glacial acetic acid/water $(125: 72: 3)$.

Spray: diazotized sulphanilic acid $0.5 \mathrm{~g}$ in $100 \mathrm{ml}$ sodium carbonate $10 \%$.

Gas chromatography of PPyA, PLA, $p$-OHPAA and PAA (trimethylsilyl derivatives) was done as described previously [3]. PAA represents free plus conjugated PAA (obtained by alkaline hydrolysis).

Apparatus: F and M 810, dual column, double FLD, with Hewlett-Packard integrator $3370 \mathrm{~A}$.

Columns: stainless steel, $245 \mathrm{~cm} \times 0.32 \mathrm{~cm}, 5 \%$ GESE-52 on Chromosorb W AW DMCS 100-120 mesh.

Temperatures: oven: first, $75^{\circ} \mathrm{C}$ isothermal for $10 \mathrm{~min}$, then $75-220^{\circ} \mathrm{C}$ $\left(2^{\circ} \mathrm{C} / \mathrm{min}\right)$, and finally $220^{\circ} \mathrm{C}$ isothermal for $10 \mathrm{~min}$; injection port: $190^{\circ} \mathrm{C}$; detector: $220^{\circ} \mathrm{C}$.

Gasflows: $\mathrm{N}_{2}: 27 \mathrm{ml} / \mathrm{min} ; \mathrm{H}_{2}: 28 \mathrm{ml} / \mathrm{min}$; air: $450 \mathrm{ml} / \mathrm{min}$.

Range: $10^{2}$; attenuation: 8 ; chartspeed: $1.27 \mathrm{~cm} / \mathrm{min}$.

Gas chromatography - mass spectrometry was performed with a Jeol JMS-D100 mass spectrometer, JLC-20KP gas chromatograph combination. The mass spectra were recorded at an electron energy of $70 \mathrm{eV}$; ionizing current of $300 \mu \mathrm{A}$; accelerating voltage: $3 \mathrm{KV}$; ion source temperature: $200^{\circ} \mathrm{C}$.

By this method the identities of PPyA, PLA, o-OHPAA, MA and PAA were proved.

\section{Results}

In Table I and Fig. 1 the urinary profiles of the patient W.Z., her sister E.Z. and the other members of the family are given. In Table II serum phenylalanine and tyrosine levels are shown. In W.Z. and E.Z. urinary PPyA, PLA, $o$-OHPAA and MA are increased and in W.Z. these compounds responded to oral loading with L-phenylalanine $100 \mathrm{mg} / \mathrm{kg}$. PAA was normal and increased only weakly after loading. Benzoic acid, a metabolite produced from nonabsorbed phenylalanine by the intestinal flora [4], was practically normal in W.Z., but somewhat increased in E.Z., B.Z. and both parents, which may indicate some impairment of intestinal phenylalanine transport.

There were no signs of a decreased intestinal transport of tyrosine and histidine [5].

In W.Z. urinary phenylalanine was found to be normal except on 12-9 (normal range up to $0.20 \mathrm{mmol} / \mathrm{g}$ creatinine). The response of serum phenylalanine to oral loading with phenylalanine was completely normal [6] and different from PKU-heterozygotes [6]. Blood phenylalanine did not exceed the renal threshold and on the day of loading the urinary concentration rose 
TABLE 1

URINARY METABOLIC PROFILES OF PATIENT W.Z., HER SISTER E. AND THE OTHER FAMILY MEMBERS (mmol/g CREATININE)

Oral loading of patient $W . Z$. was done with $100 \mathrm{mg}$ L-phenylalanine. BA, benzoic acid; PA $A$, phenylacetic acid; MA, mandelic acid; phenylpyruvic acid; Phe, phenylalanine.

Crea-
tinilite

$(\mathrm{g} / \mathrm{l})$

Patient W.Z.

$\begin{array}{lllllllll}\text { Urine sample } 17 / 18-5-74 & 0.83 & 1.31 & 0.86 & 0.06 & 0.06 & 0.20 & 0.61 & 0.11 \\ \text { Urine sample } 7 / 8-6-74^{*} & 0.71 & 1.08 & 0.30 & 0.03 & 0.10 & 0.25 & 0.60 & 0.13 \\ \text { Urine sample 12-9-73 } & 1.21 & 0.53 & 0.70 & 0.04 & 0.08 & 0.22 & 0.10 & 0.35\end{array}$

W.Z.

$\begin{array}{lllllllll}\text { Before loading } & 0.98 & 0.94 & 0.32 & 0.03 & 0.08 & 0.20 & 0.63 & 0.08 \\ \text { Day of loading } & 1.19 & 0.61 & 0.56 & 0.07 & 0.21 & 0.57 & 1.78 & 0.22 \\ \text { Day after loading } & 1.35 & 1.04 & 0.33 & 0.05 & 0.11 & 0.25 & 0.62 & 0.17 \\ \text { ter E.Z. sample 5-9-74 } & 1.22 & 2.18 & 0.99 & 0.04 & 0.14 & 0.18 & 0.45 & 0.09 \\ \text { Z. } & 2.03 & 2.64 & 0.68 & - & - & - & - & - \\ \text { s. Z. } & 1.43 & 3.80 & 0.51 & -- & - & - & - & - \\ \text { Dther B.Z. } & 0.89 & 1.70 & 0.62 & - & \ldots- & -- & -- & - \\ \text { other W.Z. } & 1.46 & 0.79 & 0.33 & - & \text { Trace } & - & \text { Absent } & \text { Absent }\end{array}$

Normal adults, $n=10$

1.14 1.31 Absent Absent

or trace

* After 4 weeks of treatment with thiamine $100 \mathrm{mg} / \mathrm{day}$.

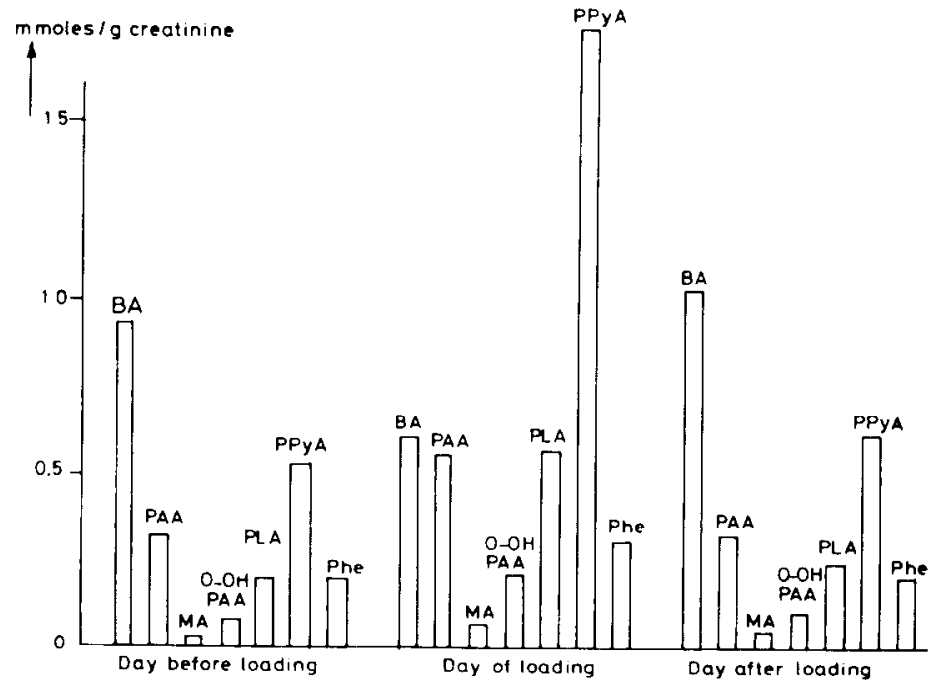

Fig. 1. Excretory pattern of phenylalanine metabolites in W.Z. before, during and after loading with L phenylalanine. $100 \mathrm{mg} / \mathrm{kg}$. 
TABLE II

SERUM PHENYLALANINE AND TYROSINE IN W.Z. AND E.Z. (mmol/1)

\begin{tabular}{lll}
\hline & Phenylalanine & Tyrosine \\
\hline W.Z. & & \\
Fasting sample on 12-9-73 & 0.08 & 0.04 \\
Fasting sample before loading on 28-11-73 & 0.05 & 0.06 \\
30 min after loading & 0.40 & 0.10 \\
60 min after loading & 0.43 & 0.13 \\
120 min after loading & 0.29 & 0.15 \\
360 min after loading & 0.10 & 0.09 \\
24 h after loading & 0.07 & 0.10 \\
E.Z. fasting sample on 14-10-74 & 0.08 & 0.07 \\
\hline
\end{tabular}

only slightly. Blood tyrosine responded well (see Table II), indicating that p-hydroxylation was essentially intact.

E.Z., with the same urinary abnormality, also had a normal fasting phenylalanine level. In this healthy girl no phenylalanine loading has been done.

Fig. 2 shows a thin-layer chromatogram of the urinary phenolic acids of W.Z. on the day of loading with L-phenylalanine.

In addition to the orange spot of $o$-OHPAA and the pink spot of PPyA, a large greyish-brown spot of an unknown compound was seen. This compound was also present on the days before and after loading, but on a much lower
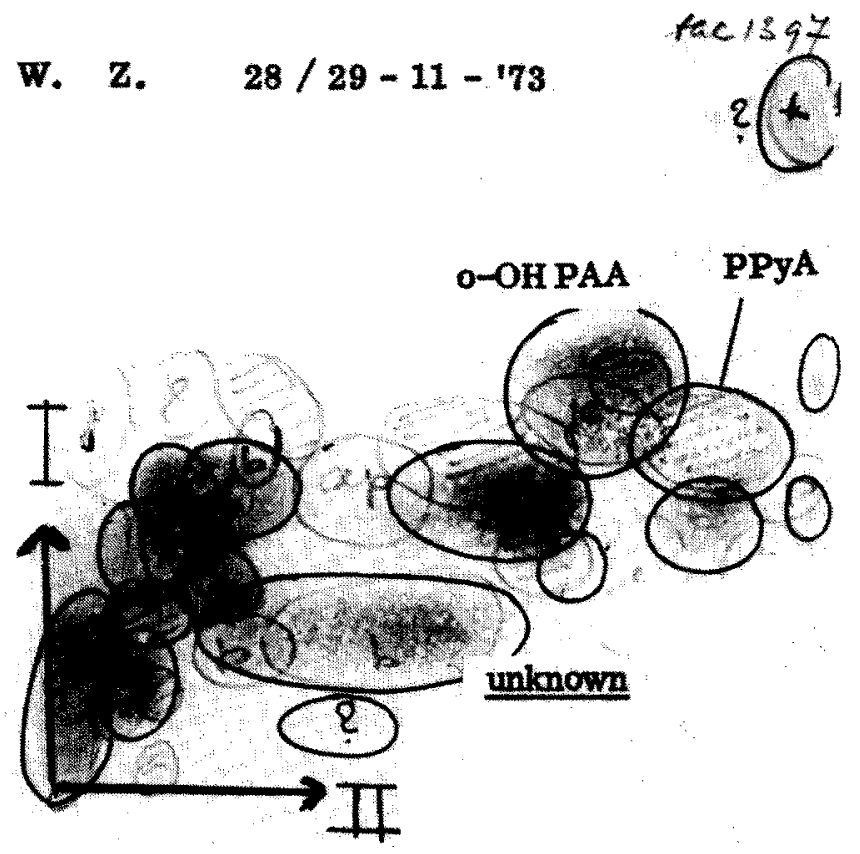

Fig. 2. Thin-layer chromatogram us urinary phenolic acids in W.Z. on the day of loading with phenylalanine, $100 \mathrm{mg} / \mathrm{kg}$. I. First solvent: isopropanol/ammonia $5 \%(8: 2)$. II. Second solvent: benzene/glacial acetic acid/water (125:72:3). 
mmolesigcreat

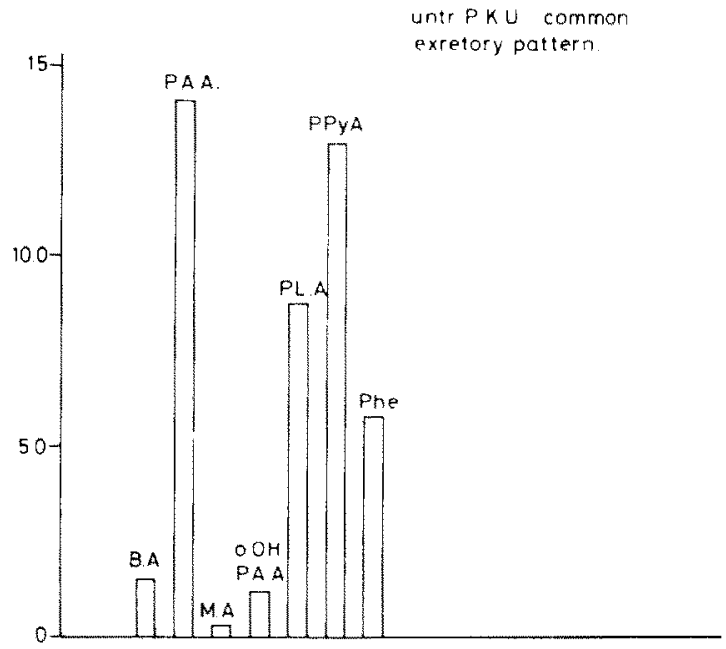

Fig. 3. Excretory pattern of phenylalanine metabolites in a patient with phenylketonuria. Compare with Fig. 1.

level. Up till now this compound has not been identified. The gas chromatogram of the trimethylsilyl compounds did not show an abnormal peak, which might represent the unknown. Isolation from a 2-dimensional Whatman-3-MM chromatogram via cutting out the area containing the compound fluorescing blue in ultra violet light, extraction with acetone and alcohol and subsequent gas chromatography of the trimethylsilylated residue yielded a number of compounds which have to be studied further. This unknown diazo-positive compound is not seen in the urine of patients with phenylketonuria.

\section{Discussion}

The patient's excretory pattern resembles that of patients with phenylketonuria in a number of respects: PPyA, PLA, o-OHPAA and MA clearly increased, however, on a much lower level. But differences also exist: urinary and blood phenylalanine are practically normal and also urinary PAA is not increased. In Fig. 3 the urinary profile of a phenylketonuric child is given for comparison. The excretory pattern of patient W.Gi., described by Chalmers and Watts [7] was comparable to some extent with that of W.Z., but fasting plasma phenylalanine was increased $(0.23 \mathrm{mM})$ and PAA was not analyzed. From Scheme 1 the interrelationship of the above mentioned metabolites can be seen. The most simple hypothesis would be a decreased oxidative decarboxylation of PPyA, supposing that normally the urinary PAA is partly formed from PPyA and partly by oxidative deamination of phenylethylamine. Also MA is supposed to originate from phenylethylamine [8]. 


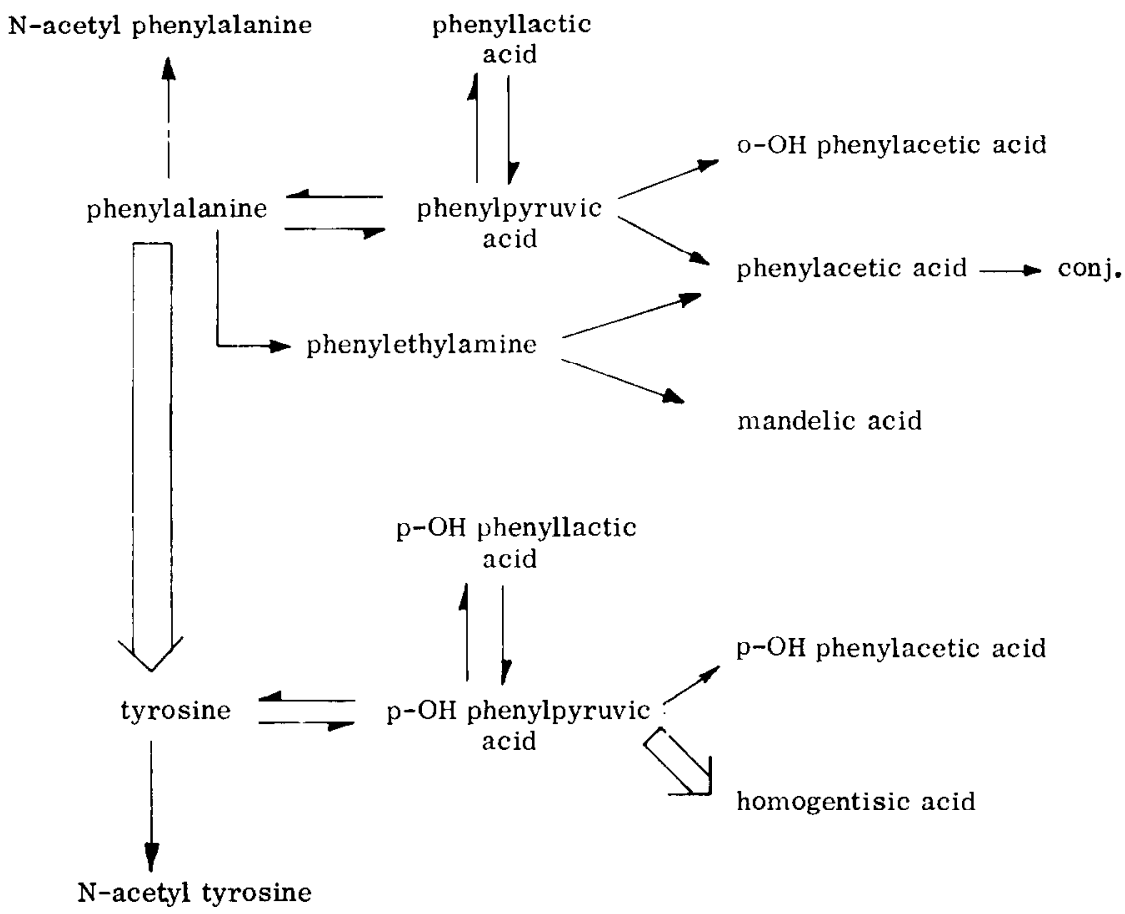

Scheme 1. Endogenous phenylalanine and tyrosine metabolism.

With this hypothesis in mind we tried the daily administration of $100 \mathrm{mg}$ thiamine for one month for correction of the anomaly in W.Z. However, no thiamine responsiveness could be demonstrated. In this connection we can mention that very little quantitative information is available about the endogenous formation of PAA from PPyA and phenylethylamine in normal and phenylketonuric individuals. In malabsorptive disease it is formed from nonabsorbed phenylalanine by the intestinal flora $[3,9]$. In untreated phenylketonuria the excretion of PAA (conjugated + free) is of the same order of magnitude as of PPyA [10]. The formation of PAA from phenylalanine is suggested to occur in human liver [11], but on the whole little is known of the location of the oxidative decarboxylation of PPyA in the human body. As far as we know, a human PPyA decarboxylase, if it occurs at all, has not been studied. Bacterial PPyA decarboxylase has been characterized by Asakawa et al. [12]. It appeared to be active for $\alpha$-keto acids having more than 6 carbon atoms in a straight chain; in addition to PPyA, $p$-hydroxyphenylpyruvate and indole pyruvate are substrates.

The transamination of phenylalanine to PPyA has also not been extensively studied. It is not even known whether a specific phenylalanine- $\alpha$-ketoglutarate or -pyruvate transaminase exists. Jacoby and La Du could not separate tyrosine 
transaminase activity from phenylalanine- and tryptophane-transaminase activity in rat liver [13]. In our laboratory we had the same experience when we tried to separate phenylalanine and tyrosine transaminase activity in rat liver homogenates by ammonium sulphate fractionation. From preliminary experiments on rat phenylalanine- $\alpha$-ketoglutarate transaminase abnormal enzyme kinetics came to light, which makes it doubtful whether such an enzyme is really operative or whether only aspecific transamination occurs.

The hypothesis of decreased phenylalanine transaminase activity in the liver alone (and not in the peripheral tissues) cannot explain the abnormality in W.Z. In that case, plasma phenylalanine would be expected to be increased and this was not so. Fellman et al. [14] described defective hepatic tyrosine transamination in a patient with tyrosyluria and tyrosinemia. They speculated also that peripheral transamination of phenylalanine could account for the production of excess of PPyA. However, it is then difficult to explain why pyruvic acid overproduction starts only when plasma phenylalanine exceeds the level of $0.9 \mathrm{mmol} / \mathrm{l}$, as is seen in patients with phenylketonuria.

It is difficult to say whether or not the anomaly in our patient W.Z. is harmful. She did not exhibit symptoms which are likely to be connected with the chemical abnormality and her sister seems to be healthy. On the other hand, cellular accumulation of PPyA may be dangerous for the developing central nervous system, as it is well known that this compound can inhibit several metabolic enzymes. Furthermore one can speculate on what can be expected from a combination of the underlying gene with a gene of the phenylketonuriatype or its variants. To answer these questions, more cases have first to be detected. This may be done by systematic screening with the ferric chloride test or with more elaborate phenolic acid chromatography. If only plasma phenylalanine is screened, abnormalities as described here will remain undiscovered.

\section{References}

1 Scriver, Ch.R. and Rosenberg, L.E. (1973) in Amino acid metabolism and its disorders (W.B. Saunders, ed.) Vol. $\mathrm{X}$ in the series Major problems in clinical pediatrics

2 Armstrong, M.D., Shaw, K.N.F. and Wall, P.E. (1956) J. Biol. Chem. 218, 293-303

3 Wadman, S.K., van der Heiden. C.. Ketting. D. and van Sprang. F.J. (1971) Clin. Chim. Acta 34. $277-287$

4 van der Heiden, C., Wauters, E.A.K., Ketting, D., Duran, M. and Wadman, S.K. (1971) Clin. Chim. Acta $34,289-296$

5 van der Heiden, C., Wadman, S.K., de Bree, P. and Wauters, E.A.K. (1972) Clin. Chim. Acta 39. 201-204

6 Justice, P., O'Flynn, M.E. and Hsia, Y.D. (1967) Lancet i, 928-929

7 Chalmers, R.A. and Watts. R.W.E. (1974) Clin. Chim. Acta 55, 281-294

8 Blau, K. (1970) Clin. Chim. Acta 27, 5-18

9 Seakins, J.W.T. (1971) Clin. Chim. Acta 35, 121-131

10 Wadman, S.K., van Sprang, F.J., van der Heiden, C. and Ketting, D. (1971) in Phenylketonuria and some other inborn errors of amino actd metabolism, pp. 65-72, Georg Thieme verlag, Stuttgart

11 Moldave, K. and Meister, A. (1957) J. Biol. Chem. 229, 463-476

12 Asakawa, T., Wada, H. and Yamano, T. (1968) Biochim. Biophys. Acta 170, 375-391

13 Jacoby, G.A. and La Du, B.N. (1962) Biochem. Biophys. Res. Commun. 8, 352--356

14 Fellman, J.H., Buist, N.R.M., Kennaway, N.G. and Swanson, R. (1972) Clin. Chim. Acta 39, 243-246 